\title{
Variação do tamanho de grão da magnésia: um exemplo da complexidade de cerâmicas refratárias
}

\author{
(Changing the magnesia grain size: an example of \\ refractory ceramics complexity)
}

\author{
M.A. L. Braulio ${ }^{I}$ D. H. Milanez ${ }^{I}$, E. Y. Sako ${ }^{I}$, L. R. M. Bittencourt ${ }^{2}$, V. C. Pandolfelli ${ }^{1}$ \\ ${ }^{\prime}$ Grupo de Engenharia de Microestrutura de Materiais, Departamento de Engenharia de Materiais, UFSCar \\ Rod. Washington Luiz, km 235, C.P. 676, S. Carlos, SP 13565-905 \\ ${ }^{2}$ Magnesita S. A. - Centro de Pesquisas e Desenvolvimento, Praça Louis Ensch 240, Contagem, MG \\ mariana_alb@yahoo.com.br,vicpando@power.ufscar.br
}

\begin{abstract}
Resumo
Concretos refratários alumina-magnésia apresentam um comportamento expansivo devido à espinelização in-situ, sendo que a fonte de magnésia e o seu tamanho de grão influenciam tal reação. Neste estudo, o aumento do tamanho de grão da magnésia utilizada resultou em expansão excessiva, gerando trincamento e deteriorando as propriedades mecânicas do material. Avaliações por microscopia eletrônica de varredura indicaram microestruturas distintas para concretos contendo diferentes tamanhos de grão $(<45$ $\mu \mathrm{m}$ e $<100 \mu \mathrm{m}$ ), após sinterização em $1500{ }^{\circ} \mathrm{C}$. Para a composição contendo a magnésia mais fina, as fases comumente observadas na literatura foram detectadas: espinélio e $\mathrm{CA}_{6}$. No entanto, o concreto contendo uma magnésia mais grosseira apresentou também a formação de forsterita e monticelita ao redor de grãos de magnésia remanescentes. Sendo assim, o objetivo deste estudo é avaliar como a alteração de apenas uma variável de um concreto refratário pode afetar significativamente as suas propriedades, devido ao desenvolvimento de microestruturas distintas.
\end{abstract}

Palavras-chave: tamanho de grão do $\mathrm{MgO}$, microestrutura, espinelização in-situ.

\begin{abstract}
The expansive behavior of alumina-magnesia refractory castable, attributed to the in-situ spinel formation, is affected by the magnesia source and its grain size. In the present work, increasing $\mathrm{MgO}$ grain size induced cracking, and, consequently, reduced the mechanical properties as a result of a large expansion. Scanning electron microscopy evaluations after firing at $1500{ }^{\circ} \mathrm{C}$ showed distinct microstructures for castables containing different grain sizes $(<45 \mu \mathrm{m}$ and $<100 \mu \mathrm{m})$. For the composition with finer magnesia, phases commonly detected in the literature were observed: spinel and $C A_{6}$. Nevertheless, besides those two phases, the castable with the coarse magnesia also presented forsterite and monticellite around the magnesia remaining grains. Hence, the objective of this work is to analyze how the refractory castable properties could be considerably affected even by changing a single parameter: the magnesia grain size.
\end{abstract}

Keywords: $\mathrm{MgO}$ grain size, microstructure, in-situ spinel formation.

\section{INTRODUÇÃO}

Um fator importante no projeto de concretos aluminamagnésia é a seleção da fonte de $\mathrm{MgO}$, uma vez que esta matéria-prima afeta várias etapas do processamento, como a moldagem, a cura e a secagem. Aspectos como o tamanho de grão da magnésia, sua pureza e reatividade influenciam tanto a hidratação como a formação de espinélio $\left(\mathrm{MgAl}_{2} \mathrm{O}_{4}\right)$.

As impurezas normalmente presentes em sínteres de magnésia são a sílica, a cálcia, o óxido de ferro, a alumina e o óxido de boro. Estas impurezas se combinam com o $\mathrm{MgO}$ e entre si, resultando em vários silicatos de cálcio e silicatos de cálcio e magnésio, entre outros. A razão $\mathrm{CaO} /$ $\mathrm{SiO}_{2}(\mathrm{C} / \mathrm{S})$ determina os compostos presentes nas partículas de $\mathrm{MgO}$ [1]: teores elevados de $\mathrm{CaO}(\mathrm{C} / \mathrm{S}>2,8)$ resultam em silicato tricálcico $\left(\mathrm{Ca}_{3} \mathrm{SiO}_{5}\right)$ e $\mathrm{CaO}$ livre, enquanto elevados teores de $\mathrm{SiO}_{2}$ geram monticelita $\left(\mathrm{CaMgSiO}_{4}\right)$ e forsterita $\left(\mathrm{Mg}_{2} \mathrm{SiO}_{4}\right)$. Esta razão também afeta às propriedades em temperaturas elevadas: com o aumento do teor de sílica (baixa razão $\mathrm{C} / \mathrm{S}$ ), a refratariedade das partículas de $\mathrm{MgO}$ se reduz (variando de aproximadamente $1850{ }^{\circ} \mathrm{C}$ para elevados teores de $\mathrm{CaO}$, para próximo a $1500{ }^{\circ} \mathrm{C}$ para elevados teores de $\mathrm{SiO}_{2}$ ) [1]. A razão $\mathrm{C} / \mathrm{S}$ e a pureza do $\mathrm{MgO}$ também interferem na espinelização insitu. Este efeito, entretanto, é verificado de modo indireto, por meio do aumento da energia de ativação para a formação de espinélio. O uso de uma magnésia de elevada área superficial implica em maior hidratação e aumento da sua atividade química, resultando em uma formação mais rápida de espinélio [2]. Deste modo, parece coerente que 
a adição de magnésias mais grosseiras pode solucionar os problemas de hidratação e espinelização excessivas, já que a hidratação é um fenômeno superficial. No entanto, esta opção pode reduzir a quantidade de espinélio formado, além de gerar resultados deletérios, como uma maior expansão volumétrica ou micro-trincamento excessivo do concreto caso o $\mathrm{MgO}$ não reaja totalmente, devido às diferenças entre o coeficiente de expansão térmica da magnésia e do espinélio e alumina [2-4].

Estudos sob o efeito do tamanho de grão da magnésia na variação linear permanente de concretos alumina-magnésia indicaram que fontes mais grosseiras de $\mathrm{MgO}$ resultam em maior expansão [5]. Tal fenômeno pode ser associado com o mecanismo de formação de poros [6], uma vez que uma maior quantidade de $\mathrm{Mg}^{2+}$ transportada resulta na geração de poros com maior dimensão. Outro aspecto associado ao tamanho de grão do $\mathrm{MgO}$ é o mecanismo de formação do espinélio. Para concretos contendo magnésia fina, o espinélio se forma principalmente pela difusão do $\mathrm{MgO}$ em grãos de alumina. Por outro lado, o uso de partículas mais grosseiras de $\mathrm{MgO}$ resulta na formação de espinélio ao redor das partículas de magnésia, ou seja, pela difusão da alumina. Foi também detetada, por meio da difração de raios $\mathrm{X}$, o desaparecimento de periclásio quando se utilizou aluminas grosseiras, enquanto o uso de $\mathrm{MgO}$ grosseiro implicou no desaparecimento de coríndon, para amostras contendo alumina e magnésia, queimadas a $1200{ }^{\circ} \mathrm{C}$ [7]. Adicionalmente, em um dos estudos consultados, a sílica se concentrou intensamente ao redor de grãos grosseiros de $\mathrm{MgO}$ [2]. Concretos alumina-magnésia apresentaram uma camada de forsterita $\left(\mathrm{Mg}_{2} \mathrm{SiO}_{4}\right)$ após sinterização à $1400{ }^{\circ} \mathrm{C}$, dificultando a reação da magnésia com a alumina [8]. A formação desta fase ocorre em temperaturas superiores a $1000{ }^{\circ} \mathrm{C}$ e é acompanhada por retração [9]. Cunha-Duncan e Bradt [10] também analisaram tal aspecto e concluíram que a formação de forsterita é inclusive termodinamicamente mais favorável que a de espinélio. Deste modo, concretos alumina-magnésia contendo microssílica podem desenvolver esta fase, dependendo do tamanho de grão da magnésia.

O tamanho de grão do $\mathrm{MgO}$ também afeta a formação de hexaluminato de cálcio $\left(\mathrm{CA}_{6}\right)$, em concretos ligados por cimento de aluminato de cálcio. Considerando que a espinelização in-situ se desenvolve anteriormente à formação de $\mathrm{CA}_{6}$, a taxa de formação de $\mathrm{CA}_{6}$ se torna mais rápida com o aumento do tamanho de grão da magnésia, em decorrência da maior disponibilidade de alumina fina, para o desenvolvimento de tal reação [5]. Considerando-se o efeito do tamanho de grão do $\mathrm{MgO}$ nas reações desenvolvidas em temperaturas elevadas, o objetivo do presente trabalho é avaliar o desenvolvimento microestrutural de concretos alumina-magnésia em função da temperatura e o seu efeito nas propriedades dos concretos. Devido às distintas fases obtidas, ficou clara a complexidade de cerâmicas refratárias, uma vez que a mudança de uma única variável resultou em situações distintas e resultados não previstos de equilíbrio de fases.

\section{MATERIAIS E MÉTODOS}

Dois tamanhos de grão da magnésia foram selecionados: $<45$ e $<100 \mu$ m, ambos com 95\%-p MgO de pureza e razão $\mathrm{C} / \mathrm{S}$ de 0,37 (Magnesita S. A., Brasil). Concretos vibrados alumina-magnésia tiveram suas composições projetadas por meio do modelo de empacotamento de Alfred com q =0,26. A matriz de tais materiais (matérias-primas finas) foi composta por 6\%-p de sínter de magnésia, 7\%-p de alumina reativa (CL370, Almatis, EUA), 6\%-p de cimento de aluminato de cálcio (Secar71, Kerneos, França), 1\%-p de microssílica (971U, Elkem, Noruega) e 15\%-p de alumina tabular fina (d $\leq 200 \mu \mathrm{m}$, Almatis, Alemanha). Para complementar as composições, aluminas tabulares grosseiras foram utilizadas como agregados ( $\mathrm{d} \leq 6 \mathrm{~mm}$, Almatis, Alemanha), resultando em um teor de água de 3,9\%-p para o $\mathrm{MgO}$ fino e 4,1\%-p para o $\mathrm{MgO}$ grosseiro.

Para os testes de resistência mecânica e de variação linear permanente (VLD), foram preparadas barras de $25 \mathrm{x}$ $25 \times 150 \mathrm{~mm}^{3}$. Após a cura $\left(50{ }^{\circ} \mathrm{C}\right.$ por $\left.1 \mathrm{dia}\right)$, secagem $(110$ ${ }^{\circ} \mathrm{C}$ por 1 dia) e calcinação $\left(600{ }^{\circ} \mathrm{C}\right.$ por $\left.5 \mathrm{~h}\right)$, as amostras foram queimadas a 1150,1300 e $1500{ }^{\circ} \mathrm{C}$ por $5 \mathrm{~h}$ (taxa de $1{ }^{\circ} \mathrm{C} / \mathrm{min}$ até o patamar). $\mathrm{O}$ módulo de ruptura foi obtido por meio do ensaio de flexão 3 pontos (ASTM C133-94) em um equipamento MTS (810, EUA). A VLD foi medida considerando-se a variação percentual na amostra antes e após queima. Adicionalmente, mediu-se a porosidade aparente pelo método de Arquimedes.

O comportamento de fluência foi avaliado por meio de um equipamento de refratariedade sob carga (modelo RUL 421 E, Netzsch). Amostras cilíndricas foram preparadas conforme a norma DIN 51053, curadas a $50{ }^{\circ} \mathrm{C}$ e secas a $110^{\circ} \mathrm{C}$ por um dia. Em seguida, foram calcinadas a $600{ }^{\circ} \mathrm{C}$ e pré-queimadas a $1550^{\circ} \mathrm{C}$ por $24 \mathrm{~h}$. As amostras foram então ensaiadas a $1450{ }^{\circ} \mathrm{C}$, permanecendo neste patamar por $24 \mathrm{~h}$. A carga de compressão aplicada foi de $0,2 \mathrm{MPa}$ e durante os ensaios acompanhou-se a deformação dos concretos devido à fluência.

As avaliações microestruturais foram obtidas mediante análises quantitativas de difração de raios X (DRX), pelo uso de um software baseado no método Rietveld (TOPAS, Bruker). Adicionalmente, utilizou-se a microscopia eletrônica de varredura (MEV) e análises de EDS para averiguar as fases desenvolvidas e sua distribuição na microestrutura dos concretos. Estas avaliações de DRX e MEV foram realizadas em amostras sinterizadas por $5 \mathrm{~h}$ em três temperaturas distintas $\left(1150,1300\right.$ e $\left.1500{ }^{\circ} \mathrm{C}\right)$. Simulações termodinâmicas também foram efetuadas, para se analisar a energia livre de Gibbs das reações e as possíveis fases de equilíbrio do sistema $\mathrm{Al}_{2} \mathrm{O}_{3}-\mathrm{MgO}-\mathrm{SiO}_{2}-\mathrm{CaO}$ (FactSage, Universidade Federal de S. Carlos, FAI).

\section{RESULTADOS E DISCUSSÃO}

Simulações termodinâmicas realizadas para a composição do concreto $\left(91,2 \%-\mathrm{p} \mathrm{Al}_{2} \mathrm{O}_{3}-1,8 \%\right.$ - $\mathrm{p} \mathrm{CaO}$ - $6 \%$-p $\mathrm{MgO}$ - $1 \%$-p $\mathrm{SiO}_{2}$ ) na temperatura de $1500{ }^{\circ} \mathrm{C}$ resultaram em 61\%-p de 
alumina, 21\%-p de espinélio, 16\%-p de $\mathrm{CA}_{6}$ e $2 \%$-p de anortita $\left(\mathrm{CaAl}_{2} \mathrm{Si}_{2} \mathrm{O}_{8}\right)$. Tal resultado está de acordo com a análise microscópica obtida para o concreto contendo o sínter de $\mathrm{MgO}$ fino $(<45 \mu \mathrm{m})$, sinterizado a $1500{ }^{\circ} \mathrm{C}$, como indica a Fig. 1a. Nesta micrografia, foi possível detectar o espinélio na matriz e o $\mathrm{CA}_{6}$ (notoriamente ao redor dos grãos de aluminas tabulares), como previsto termodinamicamente. Nesta situação, a sílica foi observada ao redor dos grãos de espinélio, indicando seu efeito na formação desta fase [11].

De modo distinto, a adição de uma magnésia mais
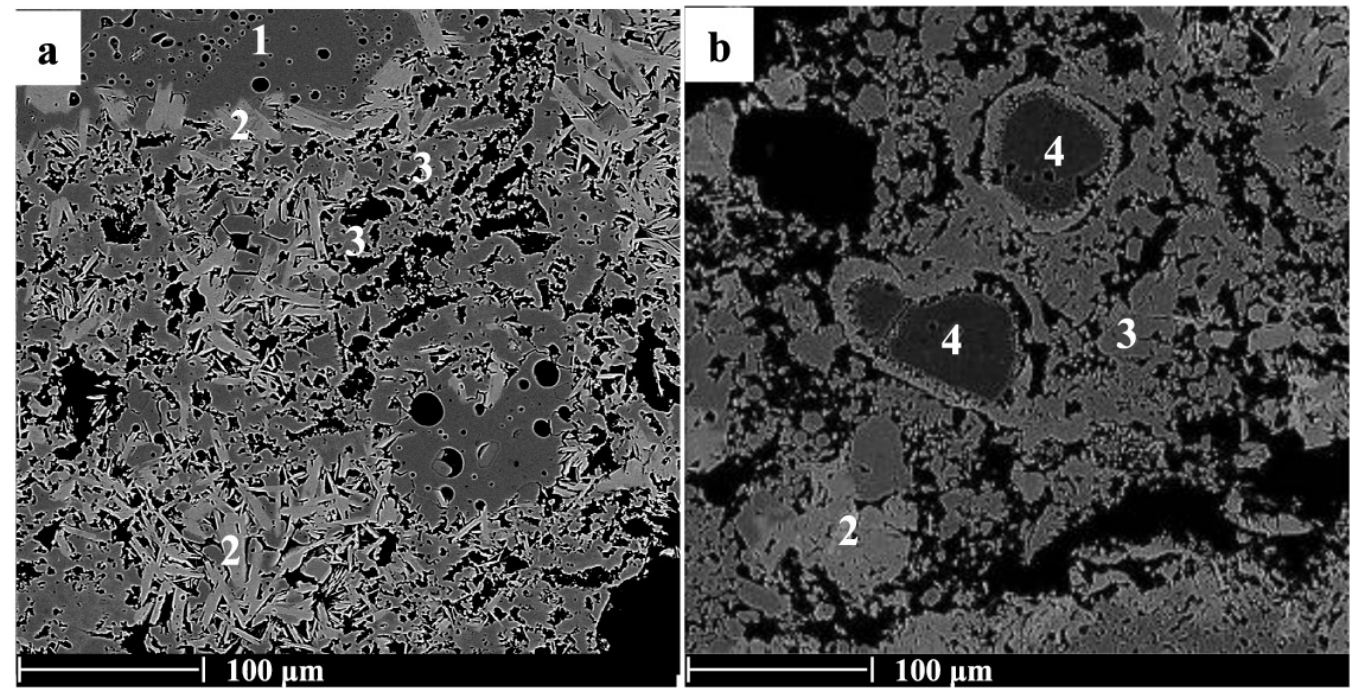

Figura 1: Micrografias obtidas por microscopia eletrônica de varredura de concretos alumina-magnésia, após sinterização a $1500{ }^{\circ} \mathrm{C}$, para (a) uma magnésia fina $(<45 \mu \mathrm{m})$ e (b) uma magnésia grosseira $(<100 \mu \mathrm{m}) ; 1=$ alumina, $2=\mathrm{CA}_{6}, 3=$ espinélio e $4=\mathrm{MgO}$ (a coroa observada ao redor destes grãos é constituída de espinélio, monticelita e forsterita).

[Figure 1: SEM micrographs of alumina-magnesia castables, after firing at $1500{ }^{\circ} \mathrm{C}$, for (a) fine magnesia $(<45 \mu \mathrm{m})$ and (b) coarse magnesia $(<100 \mu \mathrm{m}) ; 1=$ alumina, $2=\mathrm{CA}_{6}, 3=$ spinel and $4=\mathrm{MgO}$ (the crown detected around these grains is composed by spinel, monticellite and forsterite).]

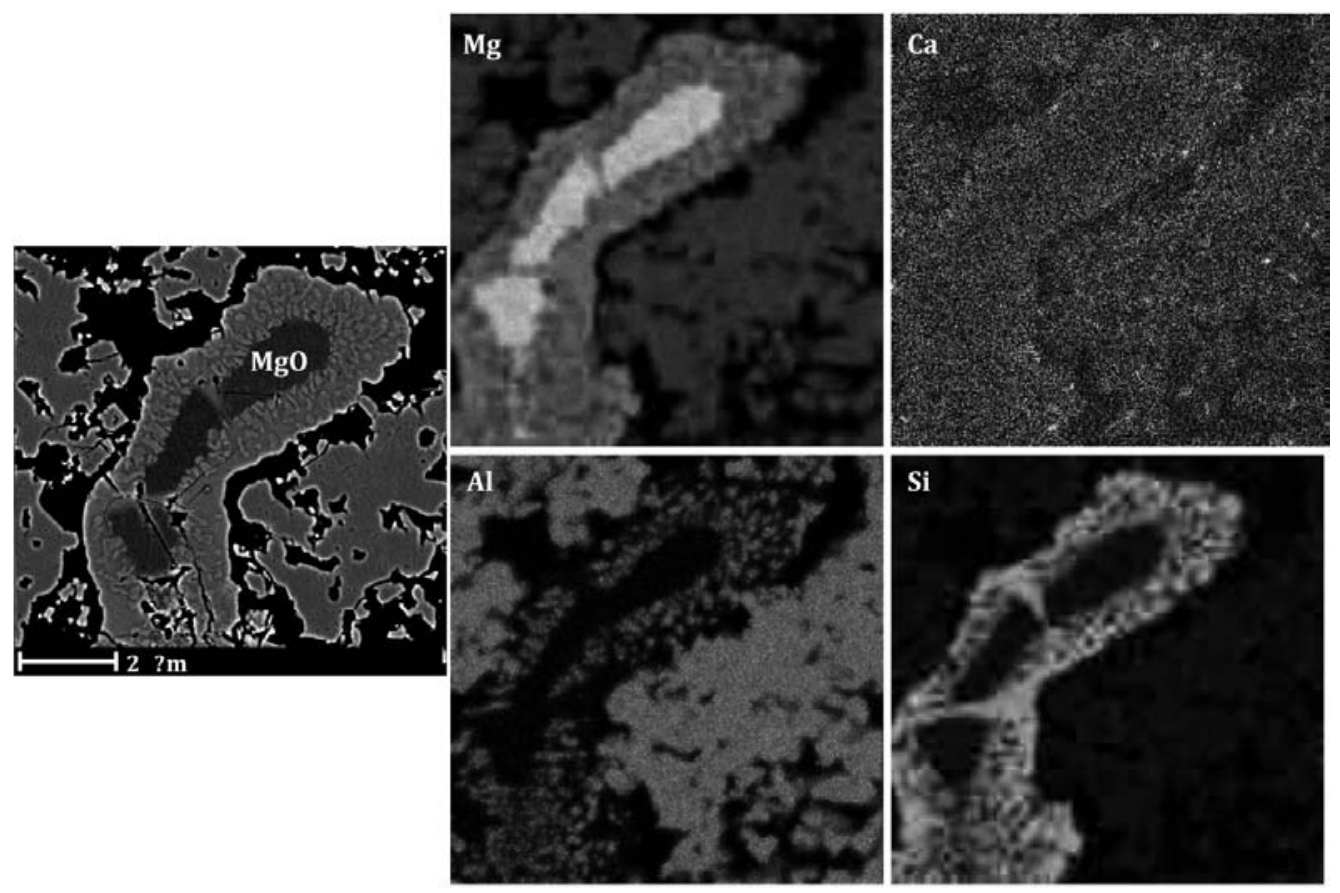

Figura 2: Micrografias obtidas por microscopia eletrônica de varredura de camada de forsterita $(\mathrm{Mg}+\mathrm{Si})$, monticelita $(\mathrm{Ca}+\mathrm{Mg}+\mathrm{Si})$ e espinélio $(\mathrm{Mg}+\mathrm{Al})$ ao redor de um grão de $\mathrm{MgO}$, detectada no concreto contendo o sínter mais grosseiro $(<100 \mu \mathrm{m})$, após queima a $1500{ }^{\circ} \mathrm{C}[12]$.

[Figure 2: SEM micrographs of forsterite $(\mathrm{Mg}+\mathrm{Si})$, monticellite $(\mathrm{Ca}+\mathrm{Mg}+\mathrm{Si})$ and spinel $(\mathrm{Mg}+\mathrm{Al})$ layer around a $\mathrm{MgO}$ grain, detected for the coarser dead-burnt containing castable $(<100 \mu \mathrm{m})$, after firing at $1500{ }^{\circ} \mathrm{C}$ [12].] 
grosseira $(<100 \mu \mathrm{m})$ resultou, após queima a $1500{ }^{\circ} \mathrm{C}$, em fases não previstas pelo diagrama de equilíbrio. Além de apresentar espinélio, alumina e $\mathrm{CA}_{6}$ como no caso anterior, forsterita $\left(\mathrm{Mg}_{2} \mathrm{SiO}_{4}\right)$ e monticelita $\left(\mathrm{CaMgSiO}_{4}\right)$ foram observadas por EDS ao redor de grãos de magnésia não reagidos totalmente (Fig. 1b). Este resultado indica o efeito da cinética no desenvolvimento microestrutural de concretos alumina-magnésia. Uma vez que a velocidade de reação é mais lenta para a magnésia mais grosseira, houve a possibilidade de reação entre o $\mathrm{MgO}$ e a sílica e cálcia, gerando as fases mencionadas acima. A Fig. 2 evidencia o desenvolvimento destas duas fases, pela presença de $\mathrm{Si} \mathrm{e} \mathrm{Ca}$ ao redor de um grão de $\mathrm{MgO}$ [12].

Devido às variações microestruturais observadas (Fig. 1), as propriedades dos concretos contendo diferentes tamanhos de grão de magnésia foram consideravelmente distintas [12]. A Fig. 3 apresenta a resistência mecânica e a porosidade aparente em função da variação linear dimensional (VLD) para estes dois materiais, queimados a 1150,1300 e $1500{ }^{\circ} \mathrm{C}$. Como consequiência da sua expansão excessiva (representada pelo elevado valor de VLD), a amostra contendo $\mathrm{MgO}$ grosseiro apresentou queda na resistência mecânica e aumento na porosidade aparente entre 1300 e $1500{ }^{\circ} \mathrm{C}$, que é a faixa de temperatura de formação de espinélio e $\mathrm{CA}_{6}$.

Adicionalmente, apesar dos grãos grosseiros favorecerem a resistência á fluência, este efeito não foi observado para o concreto contendo $\mathrm{MgO}<100 \mu \mathrm{m}$. Como um grande número de trincas foi desenvolvido e devido à formação de monticelita, a obtenção da curva de fluência para a composição contendo a magnésia grosseira (M95 < $100 \mu \mathrm{m}$ ) contendo $1 \%$-p de microssílica não pôde ser obtida. Mesmo com a redução do teor de sílica (de 1 para $0,5 \%$ p), que resultou na diminuição da porosidade aparente e da expansão, a resistência à fluência continuou sendo inferior a dos concretos contendo a fonte de $\mathrm{MgO}$ fina (M95 < 45 $\mu \mathrm{m})$, tanto para $1 \%$ quanto para $0,5 \%$-p de microssílica, como ilustra a Fig. 4.

Como indicado pelas figuras anteriores, a mudança de uma única variável (tamanho de grão do $\mathrm{MgO}$ ) afetou significativamente às propriedades dos concretos aluminamagnésia, devido ao seu efeito sobre a microestrutura desenvolvida. Para entender tamanha mudança microestrutural é importante atentar para a cinética de formação de espinélio e de $\mathrm{CA}_{6}$ para os dois concretos estudados. Neste sentido, as análises quantitativas de DRX indicaram o desenvolvimento de $16 \%$-p de espinélio após queima a $1300{ }^{\circ} \mathrm{C}$ e $21 \%$-p desta fase a $1500{ }^{\circ} \mathrm{C}$ para o concreto contendo magnésia fina $(<45 \mu \mathrm{m})$. Por outro lado, o concreto composto pela magnésia mais grosseira $(<100 \mu \mathrm{m})$ resultou em apenas 4\%-p de espinélio após queima a 1300 ${ }^{\circ} \mathrm{Ce} 16 \%$-p deste a $1500{ }^{\circ} \mathrm{C}$, indicando sua cinética de reação mais lenta. Quanto à formação de $\mathrm{CA}_{6}$, foram identificados $14 \%$-p no concreto contendo $\mathrm{MgO}$ fino $(<45 \mu \mathrm{m})$ e $16 \%$ p para aquele composto por $\mathrm{MgO}$ grosseiro $(<100 \mu \mathrm{m})$, após queima a $1500{ }^{\circ} \mathrm{C}$. Este teor levemente superior para o concreto contendo $\mathrm{MgO}$ grosseiro está em sintonia com os resultados apresentados por Ide e colaboradores [5].
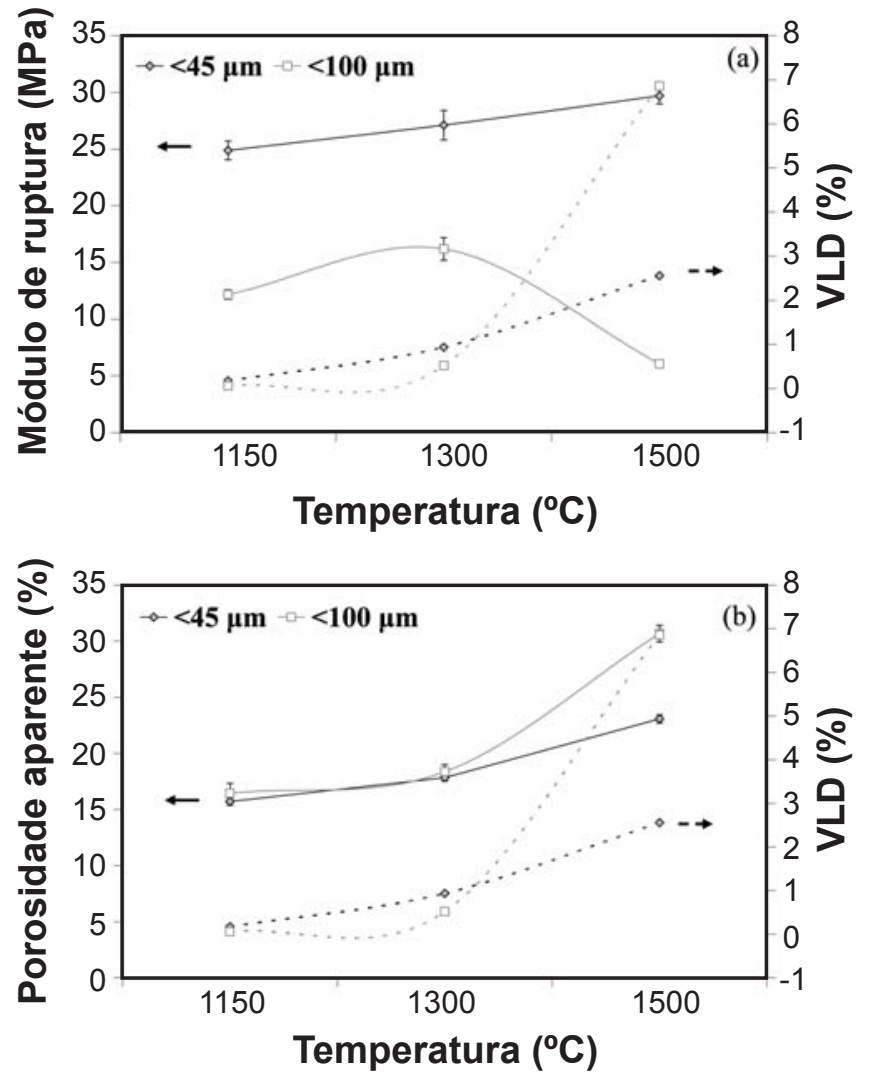

Figura 3: (a) Resistência mecânica e (b) porosidade aparente $\mathrm{x}$ variação linear dimensional de concretos alumina-magnésia contendo diferentes tamanhos de grão $(<45$ e $<100 \mu \mathrm{m})$ [12].

[Figure 3: (a) Mechanical strength and (b) apparent porosity $x$ PLE (permanent linear expansion) for alumina-magnesia castables containing different grain sizes $(<45 e<100 \mu \mathrm{m})$ [12].]

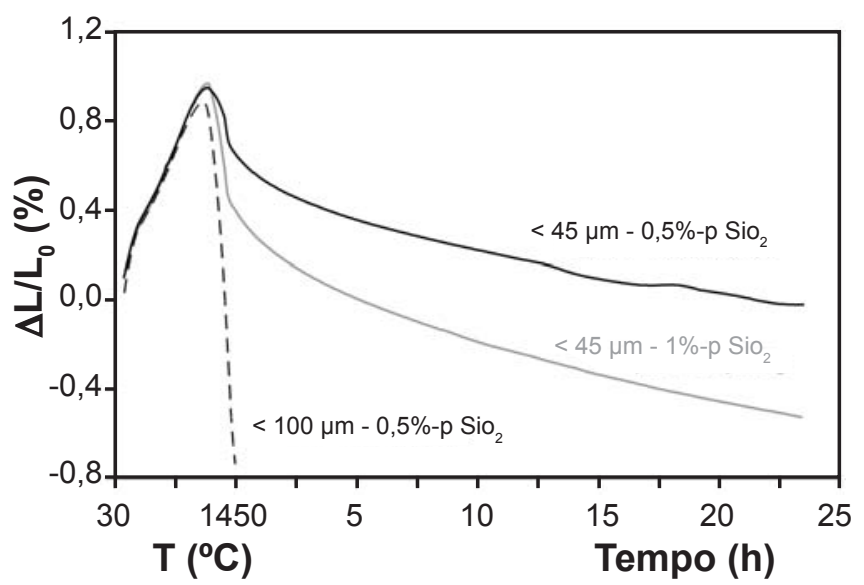

Figura 4: Resistência à fluência dos concretos alumina-magnésia contendo magnésias de tamanhos de grãos distintos $(<45$ e $<100$ $\mu \mathrm{m})$ e 0,5 ou $1 \%$-p de microssílica [12].

[Figure 4: Creep resistance of alumina-magnesia castables containing different magnesia grain sizes $(<45 e<100 \mu \mathrm{m})$ and 0.5 or 1 wt.\% of microsilica [12].]

Complementarmente às análises de DRX, a Fig. 5 indica as microestruturas dos concretos queimados a $1300{ }^{\circ} \mathrm{C} \mathrm{e}$ $1500{ }^{\circ} \mathrm{C}$, para os dois tamanhos de grão da magnésia $(<$ $45 \mu \mathrm{m} \mathrm{e}<100 \mu \mathrm{m})$. Dois aspectos devem ser destacados 


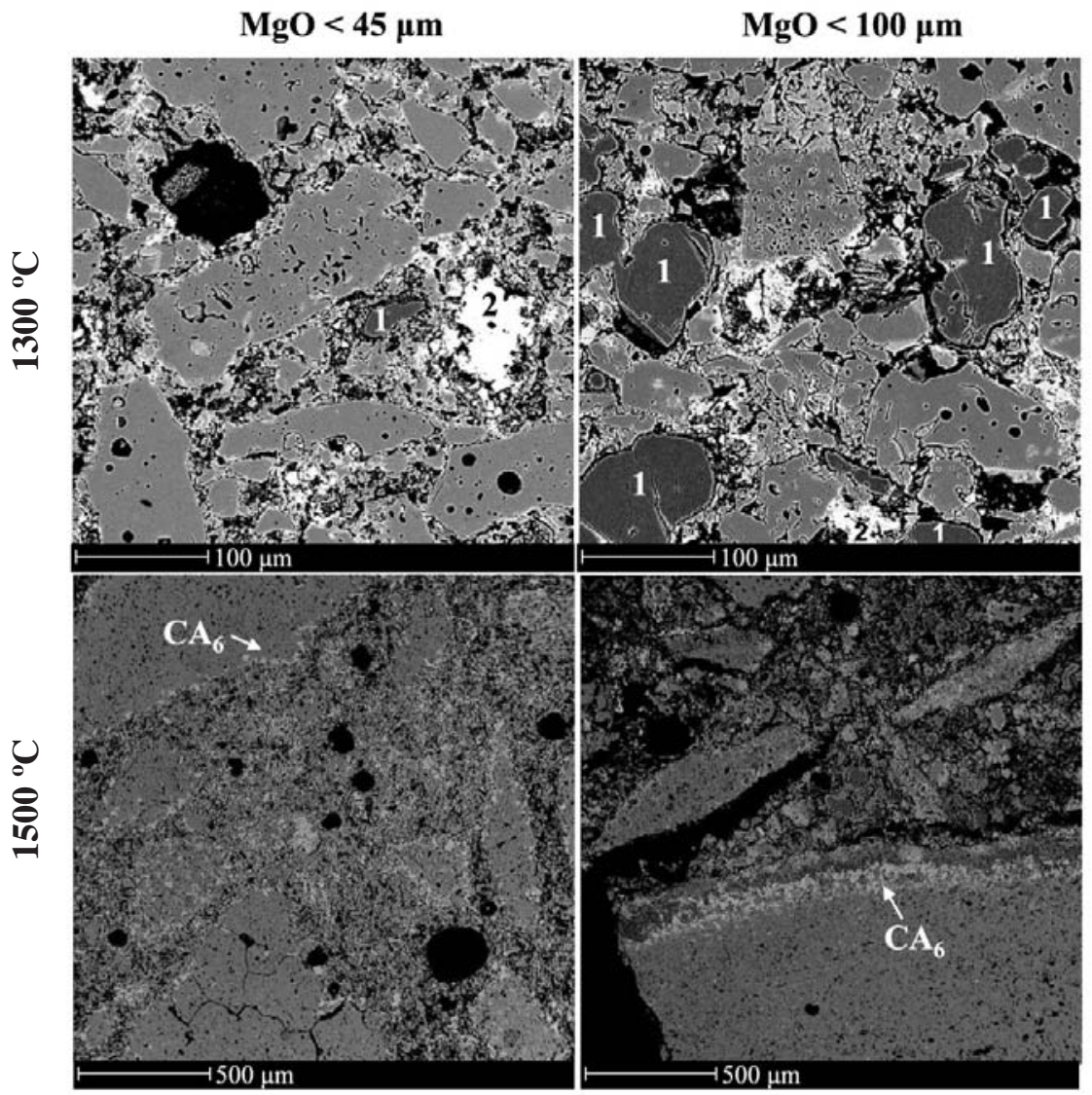

Figura 5: Micrografias obtidas por microscopia eletrônica de varredura dos concretos alumina-magnésia contendo $\mathrm{MgO}<45 \mu \mathrm{m}$ e $<100 \mu \mathrm{m}$, após queima a 1300 e $1500{ }^{\circ} \mathrm{C}\left(1=\mathrm{MgO}\right.$ e $\left.2=\mathrm{CA}_{2}\right)$.

[Figure 5: SEM micrographs of alumina-magnesia castables containing $\mathrm{MgO}<45 \mu \mathrm{m}$ and $<100 \mu \mathrm{m}$, after firing at 1300 e $1500{ }^{\circ} \mathrm{C}\left(1=\mathrm{MgO}\right.$ e $\left.2=\mathrm{CA}_{2}\right)$.]

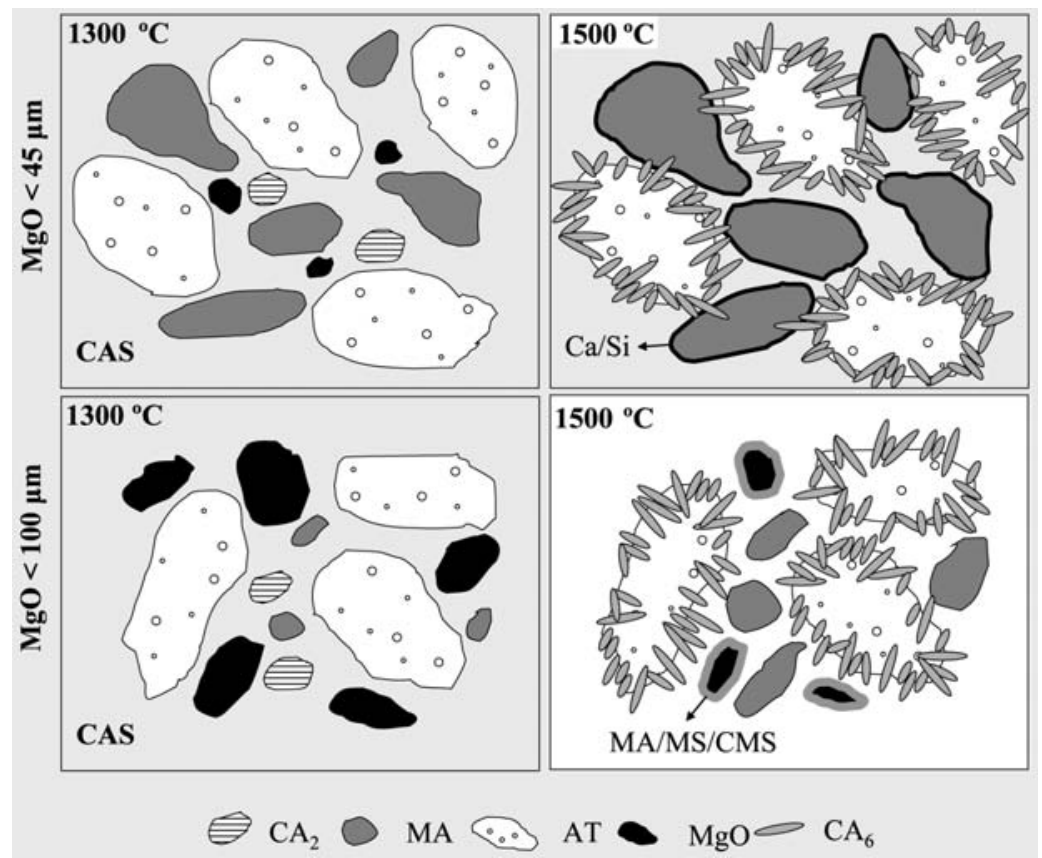

Figura 6: Mecanismo de formação de fases para os concretos alumina-magnésia contendo tamanhos de grãos distintos $(<45$ $\mu \mathrm{m}$ e $<100 \mu \mathrm{m})$, onde $\mathrm{MA}=$ espinélio, $\mathrm{AT}=$ alumina tabular, $\mathrm{CAS}=\mathrm{CaO}-\mathrm{Al}_{2} \mathrm{O}_{3}-\mathrm{SiO}_{2}, \mathrm{MS}=$ forsterita e CMS $=$ monticelita . [Figure 6: Mechanism of phases formation for alumina-magnesia castables containing different grain sizes $(<45 \mu m$ and $<$ $100 \mu \mathrm{m})$, where $\mathrm{MA}=$ spinel, $\mathrm{AT}=$ tabular alumina, $\mathrm{CAS}=\mathrm{CaO}-\mathrm{Al}_{2} \mathrm{O}_{3}-\mathrm{SiO}_{2}, \mathrm{MS}=$ forsterite e $\mathrm{CMS}=$ monticellite.] 
nestas micrografias: (i) a maior presença de grãos de $\mathrm{MgO}$ a $1300{ }^{\circ} \mathrm{C}$ para o sínter mais grosseiro e (ii) o elevado trincamento de tal concreto, após queima a $1500{ }^{\circ} \mathrm{C}$.

Considerando-se as micrografias apresentadas e os resultados de DRX, um mecanismo de reação é proposto (Fig. 6), para a compreensão dos motivos que definem o porquê a alteração de uma única variável (tamanho de grão do $\mathrm{MgO}$ ) resultou em efeitos tão distintos na microestrutura do material. No caso do sínter mais fino $(<45 \mu \mathrm{m})$, a $1300{ }^{\circ} \mathrm{C}$ praticamente toda a magnésia foi consumida na formação de espinélio. Além da presença de $\mathrm{CA}_{2}$, a matriz deve possuir também fases do sistema $\mathrm{CaO}-\mathrm{Al}_{2} \mathrm{O}_{3}-\mathrm{SiO}_{2}(\mathrm{CAS})$, tais como a anortita e a guelenita. Já a $1500{ }^{\circ} \mathrm{C}$, o $\mathrm{CaO}$ reage com a alumina, resultando na formação de $\mathrm{CA}_{6}$ no contorno dos grãos da alumina tabular. Adicionalmente, íons $\mathrm{Si}^{4+}$ e $\mathrm{Ca}^{2+}$ são encontrados ao redor dos grãos de espinélio. De forma distinta, para o $\mathrm{MgO}$ mais grosseiro, uma grande quantidade de magnésia está presente a $1300{ }^{\circ} \mathrm{C}$, devido à sua menor dissolução. Semelhante ao sínter fino, $\mathrm{CaO}, \mathrm{SiO}_{2}$ e $\mathrm{Al}_{2} \mathrm{O}_{3}$ devem estar combinados em tal temperatura. A $1500{ }^{\circ} \mathrm{C}$, uma parcela do $\mathrm{CaO}$ e da $\mathrm{Al}_{2} \mathrm{O}_{3}$ reagem entre si, gerando $\mathrm{CA}_{6}$. No entanto, diferentemente do sínter mais fino onde o $\mathrm{MgO}$ é consumido em temperaturas próximas a $1300{ }^{\circ} \mathrm{C}$, uma parcela de $\mathrm{SiO}_{2}$ e $\mathrm{CaO}$ que estavam combinadas com a $\mathrm{Al}_{2} \mathrm{O}_{3}$ a $1300^{\circ} \mathrm{C}$ [13] reage com o $\mathrm{MgO}$, resultando em forsterita e monticelita simultaneamente à formação de espinélio e $\mathrm{CA}_{6}$. Estas reações são comprovadas por simulações termodinâmicas, que indicam uma energia livre de Gibbs mais negativa a $1500{ }^{\circ} \mathrm{C}$ para a monticelita $(-107 \mathrm{~kJ} / \mathrm{mol})$ e para forsterita $(-58 \mathrm{~kJ} / \mathrm{mol})$ quando comparadas à formação de espinélio $(-35 \mathrm{~kJ} / \mathrm{mol})$.

\section{CONCLUSÕES}

A variação da granulometria da magnésia em concretos espinelizados in-situ gerou alterações significativas nas propriedades e microestrutura do material. O uso de um sínter mais grosseiro resultou em fases não usuais para esta classe de concreto, como a forsterita e monticelita. Adicionalmente, as distintas microestruturas observadas resultaram em diferentes comportamentos nas propriedades termo-mecânicas e no comportamento expansivo do material. Sendo assim, este trabalho indicou a complexidade envolvida nas cerâmicas refratárias, uma vez que uma única variável afetou de modo marcante o desempenho do material. Tais resultados destacam a necessidade de controle sobre as matérias-primas refratárias utilizadas, uma vez que seu desempenho será afetado durante a aplicação.

\section{AGRADECIMENTOS}

Os autores agradecem à FIRE (Federation for International Refractory Research and Education), à Magnesita S. A. (Brasil) e à FAPESP pelo suporte a este trabalho.

\section{REFERÊNCIAS}

[1] R. A. Landy, Magnesia Refractories - Refractories Handbook, Marcel Dekker Inc., EUA (2004) 109.

[2] J. Soudier, Unified International Conference on Refractories, The Am. Ceram. Soc., Orlando, EUA (2005) 682.

[3] S. Zhang, W. E. Lee, Spinel-Containing Refractories Refractories Handbook, Marcel Dekker Inc., EUA (2004) 215.

[4] M. Rigaud, S. Palco, N. Wang, Unified International Technical Conference on Refractories, Technical Association of Refractories - Japan, Kyoto, Japão (1995) 387.

[5] K. Ide, T. Suzuki, K. Asano, T. Nishi, T. Isobe, H. Ichikawa, Expansion Behavior of Alumina-Magnesia Castables, J. Tech. Assoc. Refract. 25, 3 (2005) 202.

[6] Y. Kyota, Unified International Technical Conference on Refractories, German Refractories Association, Dresden, Alemanha (2007) 546.

[7] J. Mori, Y. Toritani, S. Tanaka, Unified International Technical Conference on Refractories, Technical Association of Refractories - Japan, Kyoto, Japão (1995) 171.

[8] H. Sapoolaky, K. G. Ahari, W. E. Lee, Influence of in situ formation on microstructural evolution and properties of castables refractories, Ceram. Int. 28 (2002) 487.

[9] B. Myhre, B. Sandberg, A. M. Hundere, Congreso ALAFAR 1997, Asociacion Latinoamericana de Fabricantes de Refractarios, San Juan, Porto Rico (1997) 10.

[10] F. N. Cunha Duncan, R. C. Bradt, Synthesis of magnesium aluminate spinels from bauxites and magnesias, J. Am. Ceram. Soc. 85, 12 (2002) 2995.

[11] M. A. L. Braulio, L. R. M. Bittencourt, J. Poirier, V. C. Pandolfelli, Microsilica effects on cement bonded aluminamagnesia refractory castables, J. Tech. Assoc. Refract. 28, 3 (2008) 180.

[12] M.A. L. Braulio, L. R. M. Bittencourt, V. C. Pandolfelli, Magnesia grain size effect on in-situ spinel refractory castables, J. Eur. Ceram. Soc. 28, 15 (2008) 2845.

[13] F. Simonin, C. Olagnon, S. Maximilien, Thermomechanical behavior of high-alumina refractory castables with synthetic spinel additions, J. Am. Ceram. Soc. 83, 10 (2000) 2481.

(Rec.09/05/2008, Ac. 05/12/2008) 